\title{
Schwierigkeiten mit der kritischen Geographie
}

\author{
Benedikt Korf \\ Department of Geography, University of Zurich, Winterthurerstrasse 190, 8057, Zürich, Switzerland \\ Correspondence: Benedikt Korf (benedikt.korf@geo.uzh.ch)
}

Received: 20 August 2018 - Revised: 2 May 2019 - Accepted: 12 May 2019 - Published: 14 June 2019

\begin{abstract}
Kurzfassung. This paper takes Foucault's and Sloterdijk's reception of the Greek cynics as an intellectual resource to critically examine critical geography's moralizing high ground. I analyse how, in 1983, Foucault and Sloterdijk paint the cynical impulse as a political practice of provocative truth-telling against the moral high-grounds of the dogmatic left of the 1970s: For Foucault and Sloterdijk, the cynics are anti-dogmatic, antitheoretical and anti-scholastic. I will argue, however, that the cynical impulse is itself in danger of speaking from the moral high ground of anti-critique, a disposition that needs the anti-dote of skepticism.
\end{abstract}

1983 im Oktober und November - Michel Foucault, der berühmte französische Philosoph, hält in Berkeley sechs Vorlesungen zur parrhêsía, zum „Wahrsprechen“, wie es in der deutschen Übersetzung heisst (vgl. Foucault, 2001). Er ist am Zenit seines Ruhmes angelangt. Der französische Poststrukturalismus feiert als French Theory seinen Durchbruch in den amerikanischen Cultural Studies - und Foucault ist neben Jacques Derrida einer ihrer grossen Helden (Cusset, 2008). Kurze Zeit danach, in seinen letzten fünf Vorlesungen am Collège de France vom 29 Februar, vom 7, 14, 21 und 28 März 1984 - wenige Monate vor seinem Tod - beschäftigt sich Foucault noch einmal, wie schon in Berkeley, ausgiebigst mit den antiken Kynikerinnen, insbesondere mit Diogenes, und ihrer Praxis der parrhêsía, die sich im Mut zur Wahrheit zeige. In seiner Vorlesung vom 29 Februar 1984 nimmt Foucault dabei kurz Notiz ,von jemandem namens Sloterdijk ... “ und von seinem Buch „,mit dem feierlichen Titel Kritik der zynischen Vernunft ... Es ist ein zweibändiges Werk, über das ich nichts weiss“ (Foucault, 1984/2010:236).

In der Tat: 1983 erscheint im Suhrkamp-Verlag das zweibändige Werk Kritik der zynischen Vernunft, das sofort zum Bestseller wird und im linken Milieu einschlägt wie ein Blitz (vgl. Heinrichs, 2009; Kallscheuer, 1987). Peter Sloterdijk fängt damit einen Zeitgeist ein, der von einer gewissen Erschöpfung und Ermattung an den dogmatischen Debatten marxistischer Linker in den 1970er Jahren geprägt ist: ,nach dem Debakel des ,linken` Aktionismus, des Terrors und sei- ner Multiplikation im Antiterror ... [geht] die kritische ,Stimmung ' nostalgisch nach innen" (Sloterdijk, 1983:24): die Revolutionäre von 1968 beginnen es sich in den Institutionen einzurichten. Sloterdijk setzt gegenüber der in dieser historischen Konstellation in der kritischen Sozialwissenschaft noch immer einflussreichen Kritischen Theorie ${ }^{1}$ einen ironischen Kontrapunkt: Er seziert die Widersprüche eines gesellschaftlichen Milieus, das sich über seine AdornoLektüre eine gesellschaftskritische Moralsphäre bewahrt, zugleich aber „das Spiel mitspielt.“ Sloterdijk empfiehlt als Gegengift einen kynischen Impuls.

Nicht die Dogmatik einer Lehre, sondern die Wahrhaftigkeit einer Existenz stehen für Foucault und Sloterdijk im Zentrum der Lehre der Kynikerinnen. Für Sloterdijk ist Diogenes, der Kyniker, der Prototyp des „Antitheoretiker, Antidogmatiker, Antischolastiker... [der] lehrt, das Wagnis der Existenz wach und heiter auf sich zu nehmen“ (Sloterdijk, 1983:303). Der Kynismus ist eine Kritik an der Erstarrung einer Gesellschaftskritik, die es sich in den Institutionen eingerichtet hat. Für Foucault ist der Kynismus eine Subjektformation mit spezifischen Selbstpraktiken, in denen das Wahrsprechen als Idee eines unverborgenen Lebens in extremis dramatisiert wird. Diogenes' Leben ist der Skandal, der als permanente Provokation mit den gewöhnlichen Lebensfor-

\footnotetext{
${ }^{1}$ Kritische Theorie (mit Grossbuchstaben) bezeichnet hier die sogenannte „Frankfurter Schule“. Für Sloterdijk sind die Hauptprotagonisten, von denen er sich distanziert, Theodor W. Adorno (in seiner Kritik der zynischen Vernunft), später dann Jürgen Habermas (Sloterdijk, 1999) und Axel Honneth (Slotedijk, 2009a).
} 
men bricht. Für Foucault und Sloterdijk hält der Kynismus einer sich zunehmend in Widersprüche verstrickenden ,kritischen" Linken den Spiegel vor: diese sei selbst zu einer akademischen Lebensform geronnen und habe den Gang durch die Institutionen angetreten, wolle zugleich aber moralisch die Oberhand behalten.

Als Kritik an der Erstarrung kritischer Theorie besitzt der von Foucault und Sloterdijk ausgegrabene kynische Impuls auch Relevanz für eine Problematisierung heutiger Formen „kritischer“ Geographie(n). Als „kritisch“ bezeichnen sich sowohl (post-) marxistische, poststrukturalistische, feministische, postkoloniale und andere Geographien, die sich selbst nicht immer grün sind und sich gegenseitig das Label ,kritisch" absprechen (vgl. Belina et al., 2009; Best, 2009; Blomley, 2006; Goeke, 2013; Raju und Jeffrey, 2017:5; Redepenning, 2007). Trotz ihrer theoretischen Vielfalt erkennen ,sich kritische Geographien selbst noch hinreichend zuverlässig“" (Goeke, 2013:4), da sie in ihrer Selbstbeschreibung den Impetus teilen, die Welt durch eine Kombination von Theorie und Praxis radikal zu verändern: ,eine möglichst bessere Geographie der Welt entgegenzusetzen“ (Lossau, 2002:151). In der deutschsprachigen Geographie hat sich diese Vielfalt kritischer Geographien vor allem unter dem revolutionären Habitus der „Neuen Kulturgeographie“ versammelt (Steinbrink and Aufenvenne, 2017). Diese kritische Geographie ist weitgehend zum Mainstream innerhalb der Humangeographie geworden (Runkel und Everts, 2017; Steinbrink und Aufenvenne, 2017).

Ich habe meine Schwierigkeiten mit der kritischen Geographie, zumindest mit jenen Formen, die in ihrem Entlarvungsgestus repressiver Beziehungen ,etwas zu einfach geworden [sind] “ (Blomley, 2006:88), indem sie meist deutlich signalisieren, ,wo man zu stehen hat“ (Redepenning, 2007:97; Korf, 2009). In dieser „zu Überreiztheiten und Selbstgerechtigkeit neigende[n] Dynamik der Kritik“ (Edlinger, 2015:48; vgl. Korf, 2018) zeigt sich eine „Hegemonie der Einsicht, von der die Einsicht in die Hegemonie abhängt" (Düttmann, 2004:84). Wir beobachten einen wachsenden „Triumph der Kritik ... die Wonnen des Argwohns, das Vergnügen am Verdacht, die Faszination der Entlarvung“, dessen Zweck ,die Etablierung ihrer eigenen absoluten Immunität“" ist (Marquard, 1976:139f.). Kritik wird zum moralischen Kontrollinstrument eines nicht-hinterfragten Konsensus: „Der Kritiker verdinglicht seinen Gegner, er behandelt ihn wie einen Mechanismus, nicht wie eine Person. Er reklamiert für sich die volle Subjektivität (aus direktem Zugang zur Wahrheit) und spricht dem anderen eben diesen Zugang ab" (Sloterdijk, 1999:35). Gegen diese Form der Moralisierung ist schwierig anzuargumentieren, ohne gleich unter Generalverdacht gestellt zu werden (Goeke, 2013).

Im Folgenden werde ich meine Schwierigkeiten mit dieser Form kritischer Geographie indirekt, über einen Umweg skizzieren, indem ich mich an Foucaults und Sloterdijks kynischer Kritik an der kritischen Theorie abarbeite: Die Kynikerin, wie sie von Foucault und Sloterdijk gezeichnet wird, entlarvt die theoretische Scholastik, aber auch den Moralisierungsgestus bestimmter Formen von Kritik. Durch die kynische Kritik kann die Frage nach den Bedingungen der Möglichkeit einer „kritischen“ Geographie zur Sprache gebracht werden, aber der Kynismus droht sich dabei selbst in Widersprüche zu verstricken: Der Kynismus teilt mit der kritischen Disposition die Überzeugung, es „,besser“ zu wissen, denn nur vom Standpunkt aus zu wissen, was richtig ist bzw. wie die Dinge sind und sein sollten, kann eine Kritik am Bestehenden formuliert werden. Dem kynischen Gestus fehlt jedoch der skeptische Modus des Zauderns, des Hinterfragens. Was dem kynischen Gestus abgeht ist die Frage: „könnte es auch anders sein?"“ - im Sinne von: könnte meine Interpretation der Dinge auch durch eine andere ersetzt werden?

Ich werde den kynischen Impuls deshalb mit einer Prise Skepsis würzen und gegen sich selbst wenden zugunsten einer Nachdenklichkeit, die nicht immer schon weiss, wo sie zu stehen hat. Diese skeptische Disposition, die im Anschluss an Hans Blumenbergs Denkstil der Umwege und Odo Marquards „Abschied vom Prinzipiellen“ skizziert wird, propagiert „Nachdenklichkeit ermöglichende Techniken der Umständlichkeit“" (Bolz, 1999:183). Der vorliegende Text ist bereits ein erster Versuch in diese Richtung, indem er die Kritik an bestimmten Formen ,kritischer“ Geographie über den Umweg von Foucaults and Sloterdijks Kynismusrezeption formuliert.

\section{Sloterdijks Diogenes}

Am 22 April 1969 stürmten drei junge Frauen auf das Podium des Hörsaals VI der Frankfurter Universität, wo der Matador der Kritischen Theorie, Theodor W. Adorno, gerade seine Vorlesung halten wollte. Die drei Frauen umringten ihn, öffneten ihre Jacken und bedrängten ihn mit ihren nackten Brüsten. Adorno floh aus dem Hörsaal, die Aktentasche als Schutz vor sein Gesicht haltend, zutiefst verstört und bitter enttäuscht. Sloterdijk greift diese Szene in seiner Kritik der zynischen Vernunft auf: „Hier stand das nackte Fleisch, das ,Kritik“ übte“ (Sloterdijk, 1983:27). Entblösste Körper als oder statt „Kritik“" War hier ein antitheoretischer, kynischer Akt am Werk? Ja und nein, urteilt Sloterdijk, denn ohne Adorno hätte „kaum einer der Anwesenden erfahren... was Kritik bedeutet ... Recht und Unrecht, Wahres und Unwahres waren in dieser Szene unentwirrbar miteinander vermischt, in einer Weise, die typisch für Zynismus ist" (Sloterdijk, 1983:27). Das Aussprechen einer ,nackten“ Wahrheit wird zu einem aggressiven Moment, einer unwillkommenen Entblössung, die den Schleier der Konventionen zerreissen will (Sloterdijk, 1983:28). Und diese „nackte“ Wahrheit wurde in dieser Szene dem Meisterdenker der Kritischen Theorie entgegengehalten.

Mit diesen Beobachtungen eröffnet Sloterdijk seine Analyse des Zynismus als Zeitgeistphänomen, um ihn vom Kynismus des Diogenes abzugrenzen. Zynismus ist für Sloter- 
dijk das „aufgeklärte falsche Bewusstsein“ (1983:37), das gegen besseres Wissen handelt und die Zynikerin arbeitsfähig hält: „seine Falschheit ist reflexiv gefedert“ (1983:38). Der Begriff des Zynismus dient Sloterdijk als zeitdiagnostische Leitkategorie einer „Phänomenologie des Ungeistes“ (Niehues-Pröbsting, 1988:8): Als Ursache für diesen Ungeist diagnostiziert Sloterdijk eine „Stagnation der Kritischen Theorie“, in der „,das masochistische Element ... das kreative überflügelt hat ... “(1983:22). Dieser Masochismus manifestiere sich in Adornos ,Schmerz-Apriori“ und einem ,weinerlichen Negativitismus“. Und er fügt hinzu: „Kritik durchlebt trübe Tage“ (1983:24). Sloterdijk kritisiert hier die Negative Dialektik, wie sie Adorno (1970/2003) formuliert hat. Diese Form der Kritik bleibe in einem „Schmerz-Apriori“ der Betroffenheit (1983:19) gefangen und stilisiere sich als ,Spiegel des Weltbösen" (Sloterdijk, 1983:22), bleibe aber in ihrem „Nein“ zu dieser Welt verhaftet: „Wo Aufklärung als ,traurige" Wissenschaft erscheint, fördert sie wider Willen die melancholische Erstarrung“" (Sloterdijk, 1983:26). Genau hier liegt für Sloterdijk die Differenz zwischen kynischer und zynischer Haltung: der Zynismus kommt dort zum Vorschein, wo die Frechheit, die Satire, die Kritik sich den Mächtigen andient und es sich in den Institutionen bequem einrichtet (Sloterdijk, 1983:328).

Dieser zynischen Erstarrung hält Sloterdijk einen kynischen Impuls entgegen, ein Denken an der „Schmerzgrenze“ (vgl. Heinrichs, 2009:53, 56). Der Kyniker, den Sloterdijk als Vorbild vor sich sieht, ist Diogenes, „ein Hund, der beisst, wenn er Lust hat... seine Waffe ist nicht so sehr die Analyse als das Gelächter" (1983:296, 303). Für Sloterdijk verkörpert Diogenes das lebendige Gegenbild zum vergeistigten Adorno und dessen leidender Theorie: Diogenes ist der Prototyp des Antitheoretikers und Antidogmatikers, der frei von Schulzwängen das ,Wagnis der Existenz wach und heiter auf sich [nimmt]“ (1983:303). Im kynischen Impuls zeigt sich eine unglaubliche Heiterkeit, eine "fröhliche Wissenschaft" (hier spielt Sloterdijk auf Nietzsche an) und eine existenzielle Reduktion, ein „Rückzug auf das animalische Niveau“ (1983:311), wodurch sich Diogenes einen ,unverführbaren, souveränen Geist" aneignete.

Die Kynikerin, macht sich auf die Suche nach „einer existentiellen Wahrheit, die vor dem Politischen situiert ist" (Heinrichs, 2009:36, Hervorhebung im Original). Frechheit und Rückzug gehören zusammen. Dies zeigt sich in der Anekdote des Zusammentreffens von Alexander dem Grossen mit Diogenes, wo letzterer auf die vermeintliche Grosszügigkeit des Königs, Diogenes werde ein Wunsch gewährt, antwortet: „Geh mir aus der Sonne“ (vgl. Sloterdijks Version dieser Anekdote: 1983:303f.). Diogenes, das schamlose politische Tier, ist der erste, der „dem Fürsten die Wahrheit zu sagen frei genug ist" (Sloterdijk, 1983:304), weil er seine Bedürfnisse reduziert hat. Diogenes zeichnet damit „die Plattform für eine existentielle Antipolitik“ (Sloterdijk, 1983:315), die auf einer existentiellen, krisenkompatiblen
Geistesgegenwart beruht: „Politik ist das, wobei man auf alles gefasst sein muss“ (Sloterdijk, 1983:315, 319).

Diogenes liefert Sloterdijk mit seiner „Enthaltsamkeit“ den entscheidenden Gegen-Impuls zum „Mythos des Aktiven“, zum „aktivistischen Selbstbehauptungsethos“ der Neuzeit (Sloterdijk, 1983:939f.): „Wer die Enthaltungspraxis übt, gerät nicht in die Selbstfortsetzungsautomatik entfesselter Aktivismen“ (Sloterdijk, 1983:941). Für Sloterdijk (1983:940) kommen ,in einer Nicht-Praxis, einem Unterlassungshandeln, einem Geschehenlassen und NichtEingreifen höhere Einsichtsqualitäten zum Ausdruck ... als in jedem noch so durchdachten Tun“. Sloterdijk (1983:941) übernimmt hier Heideggers Begriff der Gelassenheit als sich Durchdringenlassen vom „Sichzeigen“ der Wahrheit. Auf dem Boden dieses kynischen Impulses plädiert Sloterdijk für eine Abrüstung des Subjekts (1983:685), eine Ethik des (Los-) Lassens, eine Parteinahme für das „Unterlassungshandeln" (Heinrichs, 2009:76), eines Nichteingreifens und Geschehenlassens, einer Nicht-Behinderung der Rhythmik der Welt - ein Gedanke, den Sloterdijk in Eurotaoismus (1989) vertiefen wird.

Bei Sloterdijk ist nicht nur Diogenes am Werk, sondern auch Lao-tse (vgl. Meyer, 1987:210) - und eben Heidegger (wir kommen darauf noch zurück). Doch ist Sloterdijks politische Kinetik nicht unumstritten. Während Slavoj Žižek (1989:25ff.) Sloterdijks Ridikülisierung der Gesellschaft durch Ironie und Sarkasmus noch goutierte, läuft für Jürgen Habermas (1983/85:124) der kynische Impuls, wie ihn Sloterdijk beschreibt, Gefahr, seine konstruktive Bedeutung für die Gesellschaft zu verlieren. „Die Auftritte des kynischen Kritikers sind kurz", schreibt Eberhard Sens (1987:255): „der Kyniker mag dem argumentativen Diskurs ungern Kopf und Sitzfleisch leihen." Sloterdijks kynischer Gestus entziehe sich dem gesellschaftlichen Diskurs "durch die Strategie der Verweigerung von Argumentation" (Habermas, 1983/85:123). Die Kynikerin lebe ,als Parasit von den Behauptungen der anderen" und mache sich damit von der intellektuellen Produktivität ihrer Gegner abhängig. Dabei wird es Habermas unbehaglich: ,der Kyniker nimmt die Verletzung der Integrität seines Gegenübers in Kauf“" (Habermas, 1983/85:124).

Sloterdijk, so Habermas, bleibe auf die Negation fixiert - die passiven Tugenden des Seinlassens, die Geste des Aussteigens (Habermas, 1983/85:124). So sieht es auch Raymond Geuss, für den die Position der Kynikerin,... auf nichts anderes... als auf die Ablehnung eines jeden konkreten politischen Engagements in der Welt oder mit der Welt, die ihn umgibt, [hinausläuft]" (Geuss, 2002, 2013:52). Eine taoistische Haltung des „Lassens“, des „Nicht(mehr)handelns“, die Sloterdijks Haltung zugrundeliegt (noch implizit in der Kritik, explizit dann später in Eurotaoismus), setzt eine objektiv harmonische Ordnung der Welt voraus, eine Ordnung, „für die alles, was uns als gutes Leben gilt, ohne Belang ist“" (Meyer, 2007:211). Die Geste der Negation, der Aussteigerin, basiert also auf einem bestimm- 
ten Weltbild, das Sloterdijk aber nicht expliziert und das eine konservative Grundhaltung nahelegt, Veränderungen des Istzustandes als begründungspflichtig auszuweisen.

\section{Foucaults Diogenes}

Foucaults letzte Vorlesungen zum Kynismus und zur parrhêsía, zuerst in Berkeley, dann am Collège de France, sind in der kritischen Geographie noch nicht aufgegriffen worden. Foucaults Aussagen zum Wahrsprechen der Kyniker als „Gegengift zur Macht“ (Saar, 2007:335) scheinen im Widerspruch zu stehen zu einem weit verbreiteten Foucault-Bild, das auch die Neue Kulturgeographie in ihrer Gründungsphase geprägt hat: In der dortigen Theoriediskussion rezipierte man Foucault vor allem über seinen berühmten letzten Satz in Die Ordnung der Dinge, ,dass der Mensch verschwindet wie im Meeresufer ein Gesicht im Sand" (Foucault, 1974:462). Dieser Satz wurde dahingehend interpretiert, dass Foucault das Subjekt verabschiedet habe; dass er von einem durch die „Macht der Diskurse“ eingehegten Subjekt ausgehe (vgl. Gebhardt, u.a. 2003:15f.; Glasze und Mattissek, 2009:28f.; Lossau, 2002:37ff.; Strüver, 2003:118f.). Diese Interpretation folgte weitgehend der anglophonen Foucault-Rezeption der 1990er Jahre, die sich vor allem an Foucaults Überwachen und Strafen (1976), später auch an Foucaults Begriff der Gouvernementalität, orientiert (vgl. Hannah, 2011; Philo, 2012).

Dem in diesen Schriften aufscheinenden Bild des eingehegten Subjektes scheinen Foucaults Ausführungen über die Sorge um sich, über eine Ästhetik der Existenz und eine Praxis des Wahrsprechens entgegenzustehen. Es ist deshalb auch von einem Bruch in Foucaults Denken, einer intellektuellen Teilung von frühem und spätem Foucault gesprochen worden (vgl. dazu: Saar, 2003:278ff.). Hannah (2010:298) spricht mit Blick auf Foucault als vermeintlichem „Anti-Humanist“ (im Subjektverständnis der Diskurstheorie) jedoch von einem grundlegenden Missverständnis. Ebenso Frédéric Gros, der die Vorlesungen editiert, kommentiert und dazu auch Foucaults umfangreiche Notizen der damaligen Zeit konsultiert hat. Gros schreibt: „... die Selbstpraktiken werden von Foucault nicht als eine begriffliche Neuerung vorgestellt, sondern ... als das Organisationsprinzip seines gesamten Werkes und als bereits seine ersten Schriften durchziehender roter Faden“ (Gros, 2004:627, vgl. auch Saar, 2007:236). Und den Kynikern räumt Foucault in seinen allerletzten Vorlesungen dazu eine zentrale Rolle ein: Der Kynismus, sagt Foucault, macht aus dem Leben, aus der Existenz, aus dem bios ,eine Alethurgie, eine Manifestation der Wahrheit“ (Foucault, 2010:227).

Foucault zeichnet den Kynismus als eine Subjektformation mit spezifischen Selbstpraktiken: Für Foucault ist zentral, dass die Kyniker die Idee eines unverborgenen Lebens bis zum Extrem getrieben und in der Form des schamlosen Lebens dramatisiert haben. Es ist das nackte Leben als „Hund“, als Bettler, als Tier, sogar als Sklave, das zugleich das souveräne Leben ist (Foucault, 2010:349f.). Der Kyniker ist ein wahrer, aber verkannter König, ein König des Spotts und des Elends, „,der seine Souveränität in der Entsagung verbirgt“ (Foucault, 2010:361). Sein Leben ist ein Skandal, das mit allen gewöhnlichen Lebensformen bricht: „Der Kyniker zwingt sich zum ,wahren Leben', um die anderen zu provozieren, damit sie verstehen, dass sie sich irren, auf Abwege geraten“ (Gros, 2010:456). Es ist eine Mahnung, die sich in aggressiver, kämpferischer, brutaler Weise manifestiert, nicht in feiner Ironie, wie bei Sokrates. „Es scheint“", schlussfolgert Gros (2004:650), ,als habe Foucault angesichts der Aporien einer Ethik der Existenz einerseits und einer für alle verbindlichen Moral andererseits schliesslich gedacht, die einzig legitime Ethik bestehe in Provokation und politischem Skandal.“

Bei Foucault finden wir demnach eine andere Nuancierung des kynischen Impules als bei Sloterdijk: nicht die Geste des Aussteigens und des Loslassens steht im Zentrum, sondern ,[der] innerweltliche Kampf gegen die Welt" (Foucault, 2010:438), ein Kampf, ,der sich an die Menschheit im allgemeinen wendet... gegen die Laster der Welt und die Übel der Menschen. ... Der Kyniker ... ist ein Amtsträger der ethischen Universalität" (Foucault, 2010:364f. und 391). Es ist ein innerweltlicher Aktivismus: Die Sorge um sich, die die Kynikerin in Übungen der Selbstprüfung, der Armut und Entsagung praktiziert, fällt mit der Sorge um die anderen zusammen (Foucault, 2010:404). Die Kynikerin macht ihr Leben zum Schauspiel, nicht als eine einsame Übung, sondern als eine gesellschaftliche Praxis der Provokation, in der das „wahre" Leben als ein Bruch, als ein anderes, zugleich an den Beginn einer ,anderen“ Welt appelliert (Gros, 2010:458).

Foucault verrät uns in seinen Vorlesungen nicht, wie ein heutiger Kynismus gelebt werden könnte. Er beschliesst seine letzte Vorlesung mit den kryptischen Worten ,ich hatte vor, Ihnen einige Dinge zum allgemeinen Rahmen dieser Analysen zu sagen, aber jetzt ist es zu spät" (Foucault, 2010:435). Und auch die Notizen, die er dazu noch hinterlassen hat, geben hierzu keine Auskunft. Auch in den Vorlesungen vom 29 Februar und vom 7 März 1984, in denen Foucault auf einige Bücher zum Kynismus eingeht (u.a. auch auf Sloterdijks Kritik der zynischen Vernunft, das er, wie gesagt, nicht gelesen hat), bleibt es bei kurzen Verweisen. Foucault erwähnt zwar André Glucksmanns Cynisme et Passion (1981), das eine Reflexion über die Möglichkeit, die der Kynismus in der Gegenwart haben könnte, enthalte, um im nächsten Satz ,ganz schlicht und bescheiden zur Geschichte des Kynismus in der Antike" zurückzukehren (Foucault, 2010:254). Das rhetorische Register, mit dem Foucault seine letzte öffentliche Vorlesung am Collège beschliesst, ist philologisch, nicht politisch. 


\section{Der kynische Impuls: Dialog unter Abwesenden}

„1983“ rekurriert auf die Gleichzeitigkeit von Foucaults und Sloterdijks Aneignung des kynischen Impulses. Zugleich könnte der Stil der beiden Bücher nicht unterschiedlicher sein: Foucaults Vorlesungen am Collège de France sind stark philologisch geprägt, an den Texten und ihren Kontexten des antiken Griechenlands orientiert: „Foucault, den nahen Tod vor Augen, nimmt sich darin alle Zeit der Welt, er ist von schier unendlicher Geduld mit seinen Gegenständen, seine Deutung ist liebevoll pedantisch und bis an die Grenze der Redundanz erschöpfend“ (Assheuer, 2010:55). Sloterdijk hingegen greift einige Anekdoten über Diogenes auf und inszeniert sich selbst als einen kynischen Denker, der eine fröhliche Wissenschaft betreibt, immer am Rande des Skandals und definitiv ausserhalb der anerkannten Regeln des akademischen Betriebs. Was hätte Foucault wohl von Sloterdijk aufgegriffen, hätte er ihn 1984 noch gelesen? Und was hätte Sloterdijk, der ja stark von Foucaults Ordnung der Dinge beeinflusst war (Sloterdijk, 1972), von Foucaults Vorlesungen gedacht, die er zur Zeit, als er Kritik der zynischen Vernunft schrieb, noch nicht kennen konnte, da sie ja erst danach gehalten wurden? Leider konnten Foucault und Sloterdijk sich nicht mehr über ihre Interpretationen des Kynismus austauschen. Foucault starb am 25 Juni 1984, wenige Monate nach seiner letzten Vorlesung; Sloterdijk hat jedoch den „späten“ Foucault rezipiert.

In seinem Buch Du musst dein Leben ändern (2009:234ff.) schreibt Sloterdijk über den „späten“ Foucault, dieser habe den „Durchbruch zu einer Konzeption der Philosophie als Exerzitium vollzogen." Foucaults Expedition in die Geschichte der Askesen bzw. der „Selbsttechniken“ seien eine philosophische Übung und Foucault auf dem Weg zu einer allgemeinen „Disziplinik“ (Sloterdijk, 2009:241). Dass Sloterdijk sich in diesem Buch auf Foucault bezieht, kommt nicht überraschend, ist doch der Begriff der Übung, den Sloterdijk hier ausarbeitet, auch ein zentrales Element in Foucaults Arbeiten zur Ästhetik der Existenz (vgl. Menke, 2003:284ff.). Zentral ist für Sloterdijk, dass Foucault die Macht nicht als „,behindernden Zusatz zu einem ursprünglich freien Können... “ sieht, sondern ,sie ist für das Können in allen Spielarten konstitutiv. Sie bildet überall ein Erdgeschoss, über dem ein freies Subjekt einzieht" (Sloterdijk, 2009:241). Dabei schreibt Foucault Techniken der Übung (apprentissage) eines selbst durch sich selbst (z.B. Abstinenzen, Bewusstseinsprüfungen) vielen philosophischen Schulen der Antike zu: Pythagoräern, Sokratikern und Kynikern (Foucault, 1987:285). Sloterdijk (2009:241) erwähnt jedoch nur die stoischen Autoren, die Foucault in früheren Vorlesungen am Collège (1981/82) behandelt hatte (vgl. Foucault, 2004), nicht aber den Kynismus.

Foucault (2010:234ff.) wiederum kritisiert die Leitunterscheidung zwischen antikem Kynismus und modernem Zynismus, den er bei Gehlen, Heinrich und Tillich vorfindet der aber auch bei Sloterdijk zentral ist: „Zunächst scheint mir, dass diese Autoren sehr systematisch einen eher positiv bewerteten Kynismus, nämlich den antiken Kynismus, einem negativ bewerteten Kynismus, nämlich dem modernen Kynismus, entgegensetzen“ (Foucault, 2010:236). Dabei werde der Kynismus in dieser Interpretation ,immer als eine Art Individualismus, von Selbstbehauptung, ... über die äusserste Vereinzelung der Existenz dargestellt ... sei es nun im Sinne einer Opposition als Reaktion auf die Auflösung der sozialen Strukturen der Antike oder angesichts der Absurditäten der modernen Welt“" (2010:237). Dabei laufe man Gefahr, „das für den Kynismus zentrale Problem des In-BeziehungSetzens von Lebensformen und der Manifestation der Wahrheit“ aus den Augen zu verlieren: „Die von der Wahrheit lebende Existenzform des Skandals scheint meiner Meinung nach den Kern des Kynismus auszumachen“ (2010:237). Für Foucault kann es demnach beim Kynismus nicht um Aussteigertum gehen, pace Sloterdijk.

Ähnlich wie Foucault (2010:253) wehrt sich auch Niehues-Pröbsting, auf den sich Sloterdijk prominent bezieht (Sloterdijk, 1983:954), gegen die wertende Gegenüberstellung von Kynismus und Zynismus: „Sloterdijk sprengt... das begriffsgeschichtliche Kontinuum, indem er Kynismus und Zynismus als Gegensätze konstruiert" (Niehues-Pröbsting, 1988:8). In seiner Begriffsgeschichte des Kynismus stellt Niehues-Pröbsting (1988:18f.) vielmehr die Janusköpfigkeit des Diogenes als Prototyp des Kynikers heraus, der als Mythos - Niehus-Pröbsting ruft an dieser Stelle Hans Blumenberg in Erinnerung - immer schon ,in Rezeption übergegangen“" ist, die Diogenes einerseits als den Narren, Spassmacher und Spötter zeichnet - hier scheint es mir, taucht Sloterdijks Diogenes auf; andererseits als Weisen und Philosophen, Foucaults Diogenes.

Bei allen unterschiedlichen Positionierungen teilen Foucault und Sloterdijk aber den kynischen Impuls, das ,wahre" Leben als ein anderes Leben zu zeichnen, als ein Leben, das einen Bruch vollzieht und Grenzen überschreitet (vgl. zu Foucault: Gros, 2010:459). Diesen Impuls sehen wir auch bei der kritischen Geographie nach dem cultural turn am Werk, wenn von einer „ANDEREN“ Geographie gesprochen wird (Lossau, 2002). Dieses ANDERE nimmt für sich eine Position mit einem besonderen Zugang zur Wahrheit in Anspruch, auf deren Basis die „Hegemonie der Einsicht“ (Düttmann, 2004:84) begründet wird. Wir finden diesen Rekurs auf ein anderes Leben mit privilegiertem Wahrheitszugang ideengeschichtlich noch anderweitig verortet: in der Figur des Idioten und in Heideggers Wahrheitsbegriff. All diesen Bezugnahmen auf das ANDERE liegt jedoch ein problematischer Begriff der Wahrheit zugrunde, den ich von einer skeptizistischen Perspektive aus hinterfragen werde.

\section{Der Idiot}

Byung-Chul Han hat für dieses andere Leben und dessen Zugang zur Wahrheit eine weitere antike Denkfigur 
ins Spiel gebracht: „Allein der Idiot hat Zugang zum ganz Anderen" (Han, 2014:107, Hervorhebung im Original). Es sei eine Funktion der Philosophie, den Idioten zu spielen, schreibt Han und beruft sich dabei auf Gilles Deleuze: „,Faire l'idiot' vollzieht einen Bruch mit dem Vorherrschenden ... und macht das Denken empfänglich für die Wahrheit““ (Han, 2016:44). Ganz ähnlich sieht Peter Strasser im Idioten eine ,spezifische Empfänglichkeit für die Tiefe der Erscheinungen“ (Strasser, 2017:18) am Werk, die erst aus seiner Weltfremdheit erwächst, in der sich die gewöhnlichen Dinge als die transzendenten, spirituellen erweisen. Für Han ist der Idiot deshalb ein moderner Häretiker, eine Figur des Widerstands gegen den Konformitätszwang. Seine Widerspenstigkeit der Andersheit oder Fremdheit verzögert ,die glatte Kommunikation des Gleichen“ (Han, 2014:109).

In der Antike war der idiotes noch nicht als positiver Begriff besetzt: Der griechische idiotes lebt für sich als Einzelner im Gegensatz zur polis (Sommer, 2010:6). So wurden die Jünger Jesu mit dem Idiotismus-Verdacht denunziert, auch wenn Paulus dem entgegnet, er sei zwar unkundig in der Rede, aber nicht in der Erkenntnis (2. Korinther II, 6). Deleuze beruft sich denn auch auf den spätmittelalterlichen Nikolaus von Kues (Guattari und Deleuze, 1996:70f.), wenn er den Idioten zur Begriffsperson erklärt - als Privatdenker, der aus sich selbst denkt. Nikolaus von Kues formt die Figur des Idioten als Angriff gegen einen Typus des Gelehrten der spätmittelalterlichen Scholastik (als Buchwissenschaft), wohingegen er ,eine Hinwendung zur Betrachtung der Welt anmahnt" (de Boer, 2003:214). Der idiota will das Elementare, das Einfache, das Klare (Flasch, 2008:254). Diesen Gestus des Idioten bei Cusanus beschreibt Ernst Cassirer (1927:52) so: ,[Die] Wahrheit bedarf keiner Zurüstungen: sie ruft auf den Strassen. Mitten im Geräusch und Getümmel des Marktes... ist sie für den, der zu hören versteht, vernehmlich.“ Hans Blumenberg interpretiert deshalb den idiota (oder Laien) bei Cusanus als Figur der Unmittelbarkeit: „Der Laie, der nicht lesen kann, ist der unbefangene Leser des Buchs der Natur“ (Blumenberg, 1986:59). Der Laie sucht die Wahrheit in der „Ursprünglichkeit der Erfahrung“ (Jaspers, 1968:69).

Doch wurde der Idiot im neuzeitlichen Denken zunehmend pathologisiert - ,der Idiot verliert seine Unschuld" (Sommer, 2010:11) und wird in die Irrenanstalt verbannt (Foucault). Erst mit Dostojewski erhält der Idiot wieder seine Irritationskraft zurück: Der Fürst Myschkin in Dostojewskis Roman „Der Idiot“ ist zugleich die Personifikation des Schwachsinns und der Unschuld, ein Fall für die Heilsgeschichte und ein Fall für die Psychatrie (Sommer, 2010:15). Walter Benjamin schreibt über den Idioten: sein „Leben strahlt ... eine bis zum Verschwinden reife Einsamkeit aus“ (Benjamin, 1966:186), und löst zugleich eine Anziehung auf seine Umgebung aus, eine Gravitationskraft, wie Benjamin betont. Für Sloterdijk (1998:481, 484) wird Dostojewskis Idiot zum ,intimen Ergänzer“ jedes begegnenden Anderen - er ist ein Engel ohne Botschaft. Der Idiot ist die
Gegenfigur zum revolutionären Erlöser. Er personifiziert eine „Leidenschaft der Passivität“ (Driesen, 2010:37).

Zugleich finden wir im Idioten Elemente kynischer Praxis - die Reduktion, das Freiwerden von Angst und Abhängigkeit, das Anderssein - nur das Lachen des Diogenes scheint zu fehlen. „Heiterkeit der Abstinenz wird die vorherrschende Laune des Idioten sein“, so Botho Strauss (2013:175). Es ist eine Heiterkeit ohne Angst: „Der heitere Idiot ... zu sein heisst, ohne eine Regung von Zukunftsunruhe, ohne Angst zu leben“ (Strauss, 2013:7). Aber ,es ist nicht so, dass der Ungesellige oder Unbeteiligte, idiotes im sozialen Sinn, bereits identisch wäre mit dem Kyniker ... “ (Strauss, 2013:10). Anders als der Kyniker lacht der Idiot nicht, sondern hüllt sich in Schweigen (Han, 2014:110) - auch dies eine Verweigerung des kommunikativen Austausches als Zeichen eines Bruches. Der Idiot: „,... der Unverbundene, der Unbegreifliches spricht. ... Privatperson. Gemeinschaftsstümper", so beschreibt ihn Botho Strauss (2013:11).

Und doch gibt es signifikante Unterschiede in den Gesten des Bruches, der Provokation, die dem kynischen Impuls wie dem ,faire l'idiot“ zugrundeliegen. Foucaults Analyse der Selbsttechniken und der kynischen Praktiken dienen dazu, dem Subjekt die Fähigkeit zum Ungehorsam zu ermöglichen, für ein kritisch-politisches Engagement. Sloterdijks kynischer Impuls - wie er ihn 1983 formuliert - ist der des Aussteigers aus der Gesellschaft - in einer Art kulturkritischem Habitus. Bernhard Lang formuliert es so: „bei Foucault ist [Diogenes] der Philosoph, der dem durch Alexander verkörperten politischen Machtmenschen gegenübertritt; bei Sloterdijk vertritt Diogenes den freien Menschen, der die Regeln der bürgerlichen Gesellschaft ebenso missachtet wie er sich den Schulzwängen etablierter philosophischer Richtungen verweigert" (Lang, 2010:175f.). Bei Foucault finden wir die (indirekte) Formulierung eines politisch-kritischen Engagements der Philosophin als Aussenseiterin der Politik; bei Sloterdijk zeigt sich hingegen eher ein kulturkritisches, auch elitäres Ressentiment à la Nietzsche, das sich zwar von Schulzwängen absetzt, aber sich zugleich als ,Denker auf der Bühne“ (Sloterdijk, 1986) inszeniert. Die Figur des Idioten bei Deleuze, Han und Strauss steht wiederum für ein wissendes Schweigen der (gesellschaftlichen) Aussenseiterin.

\section{Heidegger}

Es gibt aber eine wichtige Gemeinsamkeit bei Foucault, Han und Sloterdijk: ihr Bezug auf Heideggers Begriff der „Entbergung“ der Wahrheit. Die Erkenntnis der Wahrheit als etwas Verborgenes traut Heidegger nur wenigen Auserwählten zu (vermutlich nur sich selbst). Die Anleihen Sloterdijks bei Heidegger liegen offen zutage (vgl. Sloterdijk, 1983:369ff.; 2001), ebenso diejenigen von Han (besonders prominent in: Han, 2016:44f.). Auch bei Botho Strauss finden wir Heideggers Vokabular der Lichtung: „Keine Sehnsucht. Keine Gewissheit.... einfache Öffnung zum Licht“" 
(Strauss, 2013:175) - und Strauss' Anleihen bei Heidegger sind auch andernorts bezeugt (Strauss, 2012). Komplizierter liegt die Sache bei Foucault, der oft als „heimlicher“ Heideggerianer bezeichnet wurde. Für Gros (2010:459), den Herausgeber von Foucaults späten Vorlesungen, führte letzterer „einen geheimen Dialog mit dem Denken Heideggers über die griechische Vorstellung der Wahrheit.“ In einem seiner letzten Interviews gesteht Foucault: „Mein ganzes philosophisches Werden war durch meine Lektüre Heideggers bestimmt" (Foucault, 2007:247).

Und in der Tat kann man bestimmte Wendungen bei Foucault als eine Paraphrasierung der Heidegger'schen Metapher des Verborgenen lesen, wenn er sagt: ,Jedenfalls möchte ich zu bedenken geben, dass, wenn es stimmt, dass die abendländische Philosophie die Frage nach dem Sein vergessen hat und dass dieses Vergessen die Metaphysik ermöglichte... dass dann vielleicht auch die Frage nach dem philosophischen Leben, ich würde zwar nicht sagen, vergessen, aber doch beständig vernachlässigt wurde; sie erschien der Philosophie ... unablässig als Balast“ (Foucault, 2010:308). Und diese Vernachlässigung führte dazu, so Foucault, dass Wahrheit nur noch ,in Gestalt des wissenschaftlichen Wissens für gültig erklärt ... [wurde]“ (Foucault, 2010:308). Dem hält Foucault die Provokation als kynische Geste entgegen, die das Andere des wahren Lebens zum Vorschein bringen soll. Der Kynismus ist für ihn die ,elementarste als auch die radikalste Form“ (Foucault, 2010:309), in der sich dieses Andere als philosophische Lebensform im Unterschied zum wissenschaftlichen Wissen zeigen kann.

„Die Kyniker als die letzte Rettung?“, fragt Gros (2004:650) mit Blick auf Foucault. Ich denke, wir sollten vorsichtig sein, diese Frage positiv zu beantworten. „Der Zyniker hat das Bedürfnis, immer ,Sieger“ zu sein“, schreibt Iring Fetscher (1975:338) - auch in der Resignation: „Zynismus [wird] zu einem Synonym für Resignation angesichts einer erkannten Bedrohung...zum Ausdruck einer... wissenden Indifferenz" (Heinrich, 1966:148, 155, meine Hervorhebung). Arnold Gehlen, den Foucault in seiner Vorlesung kritisiert (Foucault, 2010:237), sieht den „kynischen Weisen“ als Prototypus des Intellektuellen, der sich in die grosse „Entlastung von der Verantwortung“ begibt, auf dem Weg zur Gesinnung, zur propagandistischen Neigung (Gehlen, 2004:11). ${ }^{2}$ Die zynische Disposition ist latent auch im Kynismus immer schon angelegt: Die Gefahr im kynischen Gestus der parrhêsía liegt in der potentiellen Rechthaberei - im Anspruch, die verborgene Wahrheit im Gestus der Provokation zu entbergen (im Sinne von Heideggers Wahrheitsbegriff).

Der Rekurs auf Heideggers Wahrheitsbegriff der Entbergung, die Foucault, Han und Sloterdijk dem kynischen (oder idiotischen) Gestus des Wahrsprechens einer anderen Wahr-

\footnotetext{
2 ... wobei hier zu erwähnen ist, dass Gehlens Intellektuellenschelte aus einer konservativen, ins Reaktionäre tendierenden politischen Positionierung heraus erfolgt.
}

heit unterlegen, läuft Gefahr, sich zu einem Gestus des wissenden und moralischen - „Siegers“ (Fletscher) zu verengen. Was dieser Wahrheitsbegriff ausklammert ist die Frage der Skepsis - des Nicht-Wissens, des Zweifels. In der Tat: Foucault hat den antiken Skeptizismus in seinen Vorlesungen ausgespart (vgl. Gros, 2004:634f., FN 21). Anhand einer anderen Anekdote aus der antiken Philosophie möchte ich im folgenden Abschnitt diese skeptische Position gegenüber dem heideggerianischen Gestus der Wahrheit vorbringen: eine thrakische Magd lacht über den Philosophen Thales und hinterfragt damit dessen Wahrheitsregime - und stellt damit sowohl die kritische als auch die kynische Entbergungsgeste der Wahrheit in Frage.

\section{Die Skeptikerin}

Neben dem Lachen des Diogenes als Provokation herrschender Wahrheitsregime kennt die hellenistische Philosophie noch ein anderes Lachen - das Lachen der Thrakerin. Platon lässt Sokrates die Geschichte von Thales, dem Astronomen, erzählen, der, ,während er sich mit dem Himmelsgewölbe beschäftigte und nach oben blickte, in einen Brunnen gefallen [sei]. Darüber habe ihn eine witzige und hübsche thrakische Dienstmagd ausgelacht..." (erzählt in Blumenberg, 1987:13f.). Für Platon war die Magd nichts anderes als eine Metapher für die Sophisten, denen er Sokrates als wahren Philosophen gegenüber stellt: Die Lächerlichkeit des Philosophen in der Lebenswelt relativiert Platon ,durch den Vergleich mit der grösseren Lächerlichkeit der über den Philosophen Lachenden selber" (Niehues-Pröbsting, 2015:33). Die Magd ist, in dieser Lesart, also eigentlich die Dumme, nicht der Philosoph.

Auch Heidegger setzt sich mit dem Spott der thrakischen Magd auseinander. In seinen Vorlesungen zur Metaphysik (WS 1935/36) wird der Sturz in den Brunnen zur Metapher für die Abgründigkeit des philosophischen Denkens (Heidegger, 1962:2ff.). Blumenberg kommentiert dies so: „Bei Heidegger ist, um im Bild zu bleiben, der Sturz des Philosophen das Kriterium dafür geworden, dass er sich auf dem richtigen Weg befindet" (Blumenberg, 1987:149). Blumenberg erkennt hier einen Bruch Heideggers mit der Phänomenologie, denn Heidegger zelebriert ,die Unerreichbarkeit des in das Unwesen des Grundes Abgestürzten von der Lebenswelt" (Blumenberg, 1987:151). Und er geht hart mit Heidegger ins Gericht: ,es geht nicht mehr um die kleine oder grosse Korrektur, sondern um die Ausnahme, die Erwählung, den Gnadenstand, von dem her nicht belehrt und eingeweiht werden kann... Der Begreifende wird daran erkannt, dass ihn niemand begreift“" (Blumenberg, 1987:158). Er entzieht sich dem Gespräch, der Zustimmung und dem Konsens. Alle anderen sind Lachende geworden.

Heideggers Weiser, so wie ihn Blumenberg zeichnet, ist eine andere Figur als der Kyniker Diogenes. Diogenes zog sich nicht aus der Welt zurück. Und es ist Diogenes, der über 
die anderen lacht. Beiden gemeinsam ist aber, dass sie ihren Wahrheitsanspruch über das Anderssein beziehen - Heideggers Weiser über den Sturz, Diogenes über die Reduktion auf das Natürliche des Menschen. Bei Heidegger geht es im Sturz um das „Sehen“ - man sieht „das Ding“. Diogenes erreicht durch die Reduktion auf das Animalische einen ,wachen Geist". In beiden Fällen geht es um eine tiefere Einsicht, die den Mägden der Lebenswelt versagt bleibt. Deshalb dürfen sie ruhig lachen. Wer zuletzt lacht, lacht am besten: Einsicht kommt nicht durch Aneignung der Lebenswelt, sondern durch Distanzierung von ihr, so Heideggers Weiser und so auch Diogenes. Im theoretischen Gestus von Foucault, Han oder Sloterdijk zeigen sich diese „Distanzierungstechniken“ (Sloterdijk, 2010:126) als Möglichkeit zur tieferen Einsicht.

Diesem Bild des Philosophen als Weisen stellt Blumenberg trocken den Phänomenologen entgegen: „Über den Phänomenologen lachen die Mägde nicht“ (Blumenberg, 1987:159). Worüber genau lacht denn die thrakische Magd? Die Anekdote, wie sie Sokrates erzählt, lässt die Magd sagen, Thales ,wolle da mit aller Leidenschaft die Dinge am Himmel zu wissen bekommen, während ihm doch schon das, was ihm vor der Nase und den Füssen läge, verborgen bleibe“ (nochmals aus Blumenberg, 1987:14). Die Magd könnte vielleicht über die Weltfremdheit oder Weltuntauglichkeit des Philosophen lachen: „Thales scheint der Welt entrückt, stürzt, und die Magd als Vertreterin der Lebenswelt lacht" (Schües, 2008:16). Vielleicht ist die Magd gar nicht so dumm: Sie könnte auch über eine grundlegende Lebenslüge der Philosophie lachen, nämlich dass erst durch eine Distanzierung von der Lebenswelt - durch Weltfremdheit theoretische Wahrheitsnähe erwachse (Cavarero, 1992:86ff.; Schües, 2008:20). Und damit würde die thrakische Magd einem kynischen Impuls folgen, gerade diese Weltfremdheit als philosophische Lebensform ,in einem Ton befreiender Heiterkeit" (Cavarero, 1992:89) in Frage zu stellen.

Die Kyniker aber haben, meint Blumenberg, das Lachen in der Philosophie professionalisiert: „Unter den philosophischen Schulen der hellenistischen Zeit ist die der Kyniker am ehesten disponiert, sich an die Stelle der spottenden Magd zu setzen und die Theoretiker aller anderen Denominationen aus dieser Position heraus verächtlich zu machen" (Blumenberg, 1987:35). Das ist nicht unbedingt als Kompliment für die Kyniker gemeint, denn das Lachen der Kyniker verzerrt die befreiende Heiterkeit der Thrakerin. Es ist der Versuch, „den Spott der Thrakerin in der Philosophie selbst zu etablieren und statt des Anfangs den Ausgang der Theorie lächerlich zu machen“ (Blumenberg, 1987:37). Diese Disposition sehen wir bei Sloterdijks Kritik am Werk, wenn er eine kynische Haltung formuliert, mit der er die Kritische Theorie - oder vielmehr die „Sophisten“ unter den Rezipienten der Kritischen Theorie - unter dem Begriff der zynischen Vernunft der Lächerlichkeit preisgibt. Der Spott der Thrakerin wird als kynische Besserwisserei selbst dogmatisch.

Was diesem Gestus fehlt ist die Massgabe: „Es könnte auch anders sein." Genau diesen Modus des Hinterfragens zeichnet für Blumenberg die Skepsis aus - „die Resistenz der Lebenswelt gegen die theoretische Einstellung - und umgekehrt" (Wetters und Fuchs, 2014:283). Schon in der antiken Skeptikerin erkennt Blumenberg eine Reaktion auf einen theoretischen Absolutismus, auf einen überhöhten Anspruch der Philosophie (Blumenberg, 1988:317). Blumenberg meint dazu: „die Besitzer des Eigentlichen ${ }^{3}$ haben es sich stets leichter gemacht, die anderen zu verspotten, die mit anderen Augen sehen wollten" (Blumenberg, 1987:30). Odo Marquard hat diesen Gedanken Blumenbergs aufgegriffen: „Die Skeptiker sind also nicht die, die prinzipiell nichts wissen; sie wissen nur nichts Prinzipielles: die Skepsis ist nicht die Apotheose der Ratlosigkeit, sondern nur Abschied vom Prinzipiellen" (Marquard, 1981:17; Hervorhebung im Original). Für Marquard verwandelt das absolute Prinzip der kritischen Theorie, ,das stets Gewissen ist, das die Wirklichkeit haben soll" (Marquard, 1981:17, Hervorhebung im Original), die faktische Wirklichkeit ins Kontingente, ins Rechtfertigungsbedürftige durch eine Tribunalisierung eben dieser Wirklichkeit.

Den „Besitzern des Eigentlichen“ hält Blumenberg die anthropologische Praxis der Rhetorik entgegen: Rhetorik ist der Inbegriff der Verzögerung, das institutionalisierte Zaudern angesichts der Vorläufigkeit unserer (theoretischen) Erkenntnis und empirischen Evidenzen - ,eine Technik, sich ein Provisorium vor allen definitiven Wahrheiten und Moralen zu arrangieren" (Blumenberg, 1981:110). Für Blumenberg ist sie - gegen alle beschleunigten Wahrheitsansprüche - „... das vernünftige Arrangement mit der Vorläufigkeit der Vernunft"“ (Blumenberg, 1981:130). Erinnern wir uns: für Platon waren es die rhetorischen Künste der Sophisten, gegen die er den Wahrheitsanspruch seiner Philosophie formulierte und seinen platonischen Sokrates antreten liess. Blumenberg jedoch zählt die Rhetorik zu einem Syndrom skeptischer Voraussetzungen, solange sie sich selbst nicht als Mittel der Wahrheit ausgibt (wie bei der Verurteilung von Sokrates). Sie ist vielmehr das Plädoyer für eine provisorische Moral.

Blumenberg schlägt eine Praxis der „Umständlichkeit“ und ,prozeduralen Phantasie“ (Blumenberg, 1971/2009:122) vor, eine immerwährende skeptisch-distanzierte Überprüfung der Vorannahmen, Bilder und Begriffe (vgl. Reichel, 2015:217). Das Lachen der Skeptikerin ist eher ein „Lachenmit“ als ein „Lachen-über“. Es ist ein genauer räumlicher Blick ,... auf Augenhöhe... nicht vertikal von oben, sondern horizontal über die Schultern“ (Köhne, 1999:413, 416). Nach Marquard (1958:54) könnte man dies einen ,interimistischen" Skeptizismus nennen, der die Welt nicht an sich in Frage stellt, aber vorschnelle Festlegungen ihrer Interpretation: „Das skeptische Ich ist vor allem Zögern“ (Marquard, 1973:152). Blumenberg bringt diese Haltung im Begriff der Nachdenklichkeit auf den Punkt: „Nachdenklich-

\footnotetext{
${ }^{3}$ Hier spielt Blumenberg auf Heideggers ,,Jargon der Eigentlichkeit“ an - der Begriff „Jargon der Eigentlichkeit“ stammt (in kritischer Absicht gesprochen) von Theodor W. Adorno (1963).
} 
keit heisst: es bleibt nicht alles so selbstverständlich, wie es war. Das ist alles“ (Blumenberg, 1981:61). Nachdenklichkeit erzeugt einen Moment der Verzögerung oder, wie es Joseph Vogl nennt, des Zauderns: „Das Zaudern ersucht um Revision... das bedeutet eine Kritik, die ihre eigene Generalisierungstendenz unterbricht“" (Vogl, 2008:109, 115). Das Zaudern bringt „Techniken der Umständlichkeit“ (Bolz, 1999:183) hervor, die Nachdenklichkeit ermöglichen.

Und doch bleibt Blumenberg auch der Skepsis gegenüber skeptisch, denn die skeptische Position des radikalen Infragestellens ,,setzt ein sich vor sich selbst verhehlendes Vertrauen in den Gang der Dinge voraus“ (Blumenberg, 1988:317f., FN 67): Die skeptische Position tendiert zu einer Ambiguität zwischen Antitraditionalismus und Konservativismus. Für Max Horkheimer, den Kritischen Theoretiker, droht sich die skeptische Haltung in einem individualistischen Quietismus einer „konfirmistischen Lebensklugheit“ (Horkheimer, 1968:227) einzurichten, die ,gegen das Interesse an einer besseren Zukunft" stehe (Horkheimer, 1968:238). Die Skepsis, so Horkheimer, sei der Zynismus des bürgerlichen Geistes, der Rückzug in die private Innerlichkeit (Horkheimer, 1968:209). ${ }^{4}$ Damit mache die Skeptikerin ihr Ich zum Fetisch. Marquard hält dem entgegen, auch die Kritikerin formuliere ihre Empörung unter den Bedingungen der spätbürgerlichen Gesellschaft: „Empörung ... ist dann - bereichert um eine Geste - das Einverständnis [mit dieser Gesellschaft]“ (Marquard, 1973:30), ohne jedoch, anders als die Skeptikerin, ihre eigenen Bedingungsmöglichkeiten kritisch zu hinterfragen. Die Skeptikerin verhalte sich nicht skeptisch gegen das Interesse an einer besseren Zukunft, sondern: gegen die Illusionen dieses Interesses (Marquard, 1973:32).

\section{Schwierigkeiten mit der kritischen Geographie}

Mein Aufsatz trägt den - Odo Marquard entlehnten ${ }^{5}$ - Titel „Schwierigkeiten mit der kritischen Geographie“ und doch wird die kritische Geographie - oder bestimmte Formen einer solchen - nicht explizit zum Objekt der Kritik. Nirgendwo zeige ich konkret auf, wo und wie bestimmte Formen kritischer Geographie defizitär sind und sich der Nachdenklichkeit verweigern, indem sie immer schon ,wissen“, was sie sehen wollen (Zahnen, 2005:212) und „wo man zu stehen hat" (Redepenning, 2007:97). Stehle ich mich hier nicht aus der Verantwortung, Ross und Reiter zu nennen (vgl. Goeke, 2013:4)? Ich denke nicht. Statt in direkter Konfrontation mit einem zu kritisierenden Denkstil in negativo das Potenzial einer skeptischen Position zu erarbeiten, habe ich hier

\footnotetext{
${ }^{4}$ In diesem Zusammenhang sollte man nicht vergessen, wann Horkheimer diesen Text schrieb - 1938: „Der Gehorsam gegen die modernen Diktaturen, denen heute der Skeptiker sich anbequemt, ist die Gefolgschaft in die Barbarei“ (Horkheimer, 1968:235).

${ }^{5} 1973$ veröffentlichte Odo Marquard eine Aufsatzsammlung unter dem Titel ,Schwierigkeiten mit der Geschichtsphilosophie" (Marquard, 1973).
}

einen Denk- und Schreibstil praktiziert, der Techniken der Umständlichkeit und prozeduralen Phantasie vollzieht, um Raum für Nachdenklichkeit zu schaffen.

Kritik an der kritischen Geographie ist ja nicht neu: Schon 2006 formulierte Blomley seine Vorbehalte gegen eine ,zu einfache" kritische Geographie, die sich an einem Entlarvungsgestus ergötzt und zugleich das akademische Spiel spielt (Blomley, 2006). Ähnliche Kritikpunkte haben Dörfler und Rothfuss (2013), Goeke (2013), Korf (2009, 2018), Redepenning (2007) und jüngst Steinbrink und Aufenvenne (2017) unter dem topos der ,Moralisierung“ auch an Teilen der deutschsprachigen Humangeographie ausgemacht. Mein Ansatz war, die von Foucault und Sloterdijk formulierte Kritik an der dogmatischen Erstarrung einer bestimmten Form kritischer Theorie aufzugreifen, um einen Raum zu schaffen, über die Kritik an der kritischen Geographie nachzudenken. Denn auch in der kynischen Kritik am Dogmatismus, die Foucault und Sloterdijk aufzeigen, liegt die Gefahr der Rechthaberei. Beide, kritische Theorie und kynisches Lachen (über sie), basieren auf Distanzierungstechniken in der „Sonderzone Theorie“ (Sloterdijk), die die Lebenswelt auf Abstand hält, um mit Heidegger die Wahrheit zu (ent)bergen. Mit anderen Worten: Kritik - und selbst die Kritik an der Kritik - inszeniert sich in der Figur des heideggerianischen Weisen, oder stärker alltagssprachlich formuliert: im Gestus der Rechthaberei.

Ich plädiere aus diesem Grund für einen Denkstil des interimistischen Skeptizismus innerhalb der Geographie - als Gegengift zu schnellen politischen oder theoretischen Positionierungen, zur heideggerianischen „Entbergungsgeste“ der Besserwisserei, zur kynischen (oder zynischen) Selbstüberhebung. Dieser Denkstil einer skeptizistischen Geographie gründet auf der Einsicht der Begrenztheit der menschlichen Wahrnehmungsfähigkeit (Hannah, 1999:21ff.) und kann - im Rückgriff auf Blumenbergs ,,skeptische Skepsis“ bzw. Marquards ,interimistischem“ Skeptizismus - als ein Denkstil der Umwege als ,permanentes Provisorium“ (Heidgen et al., 2015) beschrieben werden. Dieser Blumenberg'sche Denkstil ist experimentell und poietisch; ein Denkstil der ,am Material arbeitet, [der] sich von ihm inspirieren lässt, [der] es nicht nur formt, sondern selbst von ihm geformt ist“" (Zill, 2015:73). In der deutschsprachigen Geographie sind Elemente dieses Denkstils u.a. mit den Begriffen „Aufmerksamkeit“ (Hannah, 2015), „Beirrung“ (Korf und Verne, 2016:367; Verne, 2012:192; nach Gadamer, 1960:252), „Spurenlesen“ (Hard, 1989) und ,Takt“ (Zahnen, 2011) skizziert worden. Dieser Denkstil erfordert eine Haltung, die das Kontingente aushält - durch Hermeneutik: „Hermeneutik ist die für Menschen lebensnotwendige Kunst, sich verstehend in Kontingenzen zurecht zu finden“ (Marquard, 1981:20).

Für Foucault und Sloterdijk bot der Kynismus eine Kritik an der Erstarrung der Gesellschaftskritik und eine Selbstpraktik der Distanzierung, die das Wahrsprechen ermöglicht - in der Form der Provokation und des (Aus-) Lachens. Das kynische Hohngelächter ist jedoch nur eine Form des philo- 
sophischen Lachens - ein Hohngelächter, dass sich selbst in die Widersprüche der Besserwisserei verstrickt. Auch dieses Lachen droht dogmatisch zu werden in seinem Wahrheitsanspruch. Es verzerrt die befreiende Heiterkeit der Skeptikerin. Die Skeptikerin lacht mit statt über. Sie lacht im hermeneutischen Geist.

Datenverfügbarkeit. Es wurden keine Daten verwendet.

Interessenkonflikt. Der Autor erklärt, dass kein Interessenkonflikt besteht.

Danksagung. Dieser Text wäre nicht ohne die Ermutigung von Tobias Boos und Simon Runkel entstanden, deren Initiative eines Themenheftes zu Sloterdijk mich dazu brachte, die Gleichzeitigkeit von Foucaults und Sloterdijks Kynismusrezeption doch noch einmal genauer unter die Lupe zu nehmen. Beide gaben auch hilfreiche Hinweise zum Manuskript, ebenso zwei sehr ausführliche Gutachten. Ich habe den Text im Geiste einer Lesegruppe geschrieben, die sich unter dem Label German Theory regelmässig mit deutschsprachigen Theoretikern auseinandersetzt. Meine Blumenberg-Lektüre, aber auch Cassirers kurzer Auftritt im Text, lassen sich so erklären. Ganz besonders danke ich in diesem Zusammenhang Eberhard Rothfuss und Woody Sahr.

Begutachtung. This paper was edited by Myriam HoussayHolzschuch and reviewed by two anonymous referees.

\section{Literatur}

Adorno, T. W.: Jargon der Eigentlichkeit, Suhrkamp, Frankfurt am Main, 1963.

Adorno, T. W.: Negative Dialektik, Jargon der Eigentlichkeit, Gesammelte Schriften 6, Suhrkamp, Frankfurt am Main, 1970/2003.

Assheuer, T.: Seid furchtlos, Bürger: ,Jetzt ist es zu spät“: Die letzten Vorlesungen des Philosophen Michel Foucault, Die Zeit Nr. 18, S. 55, 29 April 2010.

Belina, B., Best, U., and Naumann, M.: Critical Geogaphy in Germany: from exclusion to inclusion via internationalization, Social Geogaphy, 5, 47-58, 2009.

Benjamin, W.: „Der Idiot“ von Dostojewski, in: Walter Benjamin, Angelus Novus. Ausgewählte Schriften 2, Suhrkamp, Frankfurt am Main, 185-189, 1966.

Best, U.: Critical Geography, International Encyclopedia of Human Geography, 345-357, https://doi.org/10.1016/B978-0080449104.00263-7, 2009,

Blomley, N.: Uncritical critical geography?, Prog. Hum. Geog., 30, 87-94, 2006.

Blumenberg, H.: Nachdenklichkeit. Dankrede, in: Jahrbuch der Deutschen Akademie für Sprache und Dichtung (1980), Lambert Schneider, Heidelberg, 57-61, 1981.
Blumenberg, H.: Die Lesbarkeit der Welt, Suhrkamp, Frankfurt am Main, 1986.

Blumenberg, H.: Das Lachen der Thrakerin: Eine Urgeschichte der Theorie, Suhrkamp, Frankfurt am Main, 1987.

Blumenberg, H.: Die Legitimität der Neuzeit, Erneuerte Ausgabe, Suhrkamp, Frankfurt am Main, 1988.

Blumenberg, H.: Anthropologische Annäherung an die Aktualität der Rhetorik, in: Wirklichkeiten, in denen wir leben, Reclam, Stuttgart, 104-136, 1971/2009.

Bolz, N.: Die Konformisten des Andersseins. Ende der Kritik, Wilhelm Fink, Paderborn, 1999.

Cassirer, E.: Individuum und Kosmos in der Philosophie der Renaissance. Studien der Bibliothek Warburg, Springer Fachmedien, Wiesbaden, 1927.

Cavarero, A.: Platon zum Trotz: Weibliche Gestalten der antiken Philosophie, Rotbuch, Berlin, 1992.

Cusset, F.: French Theory: How Foucault, Derrida, Deleuze \& Co. Transformed the Intellectual Life of the United States, University of Minnesota Press, Minneapolis, 2008.

De Boer, J.: Plädoyer für den Idioten. Bild und Gegenbild des Gelehrten in den Idiota-Dialogen des Nikolaus von Kues, Conciliium medii aevi, 6, 195-237, onlline aufrufbar: https://cma.gbv.de/ dr,cma,006,2003,a,08.pdf (letzter Zugriff: 8. Juni 2019), 2003.

Deleuze, G. und Guattari, F.: Was ist Philosophie?, Suhrkamp, Frankfurt am Main, 1996.

Dörfler, T. und Rothfuss, E.: Postkonstruktivismus - Jenseits von Postmoderne und cultural turn, Berichte zur deutschen Landeskunde 87, 195-203, 2013.

Driesen, C.: Wie Deleuze den Idioten gibt, Zeitschrift für Ideengeschichte IV (2), 37-41, 2010.

Düttmann, A. G.: Philosophie der Übertreibung, Suhrkamp, Frankfurt am Main, 2004.

Edlinger, T.: Der wunde Punkt: Vom Unbehagen an der Kritik, Suhrkamp, Berlin, 2015.

Fetscher, I.: Reflexionen über den Zynismus als Krankheit unserer Zeit, in: Denken im Schatten des Nihilismus, Herausgeber: Schwan, A., Wissenschaftliche Buchgesellschaft, Darmstadt, 334-345, 1975.

Flasch, K. und von Kues, N.: Geschichte einer Entwicklung. Vorlesungen zur Einführung in seine Philosophie, Vittorio Klostermann, Frankfurt am Main, 2008.

Foucault, M.: Die Ordnung der Dinge: Eine Archäologie der Humanwissenschaften, Suhrkamp, Frankfurt am Main, 1974.

Foucault, M.: Überwachen und Strafen: Die Geburt des Gefängnisses, Suhrkamp, Frankfurt am Main, 1976.

Foucault, M.: Zur Genealogie der Ethik: Ein Überblick über laufende Arbeiten, in: Michel Foucault. Jenseits von Strukturalismus und Hermeneutik, Herausgeber: Dreyfus, H. L. und Rabinow, P., Frankfurt am Main, 265-292, 1987.

Foucault, M.: Fearless Speech, Herausgeber: Pearson J., Semiotext(e), Los Angeles, 2001.

Foucault, M.: Hermeneutik des Subjekts: Vorlesungen am Collège de France (1981/82), Suhrkamp, Frankfurt am Main, 2004.

Foucault, M.: Ästhetik der Existenz: Schriften zur Lebenskunst, Suhrkamp, Frankfurt am Main, 2007.

Foucault, M.: Der Mut zur Wahrheit: Die Regierung des Selbst und der anderen II, Vorlesungen am Collège de France (1983/84), Suhrkamp, Berlin, 2010. 
Gadamer, H.-G.: Wahrheit und Methode, Grundzüge einer philosophischen Hermeneutik, Tübingen, J.C.B. Mohr (Paul Siebeck), 1960.

Gebhardt, H., Reuber, P., und Wolkersdorfer, G.: Kulturgeographie - Leitlinien und Perspektiven, in: Kulturgeographie: Aktuelle Ansätze und Entwicklungen, Herausgeber: Gebhardt, H., Reuber, P., und Wolkersdorfer, G., Spektrum, Heidelberg, 1-27, 2003.

Gehlen, A.: Moral und Hypermoral: Eine pluralistische Ethik, Vittorio Klostermann, Frankfurt am Main, 2004.

Geuss, R.: Privatheit: Eine Genealogie, Suhrkamp, Frankfurt am Main, 2002/2013.

Glasze, G. und Mattissek, A.: Diskursforschung in der Humangeographie: Konzeptionelle Grundlagen und empirische Operationalisierungen, in: Handbuch Diskurs und Raum, Herausgeber: Glasze, G. und Mattissek, A., Transcript, Bielefeld, 11-60, 2009.

Glucksmann, A.: Cynisme et Passion, Editions Grasset et Fasquelle, Paris, 1981.

Goeke, P.: Grenzenlose Konflikte. Programme kritischer Geographien und ihrer Folgen, Geogr. Z., 101, 1-19, 2013

Gros, F.: Situierung der Vorlesungen, in: Hermeneutik des Subjekts, Herausgeber: Foucault, M., Vorlesungen am Collège de France (1981/82), Frankfurt am Main, Suhrkamp, 616-668, 2004.

Gros, F.: Situierung der Vorlesung, in: Der Mut zur Wahrheit: Die Regierung des Selbst und der anderen II, Herausgeber: Foucault, M., Vorlesung am Collège de France (1983/1984), Suhrkamp, Berlin, 440-460, 2010.

Habermas, J.: Zwischen Heine und Heidegger. Ein Renegat der Subjektphilosophie, in: Die Neue Unübersichtlichkeit: Kleine Politische Schriften V, Herausgeber: Habermas, J., Suhrkamp, Frankfurt am Main, 121-125, 1983/1985.

Han, B.: Psychopolitik: Neoliberalismus und die neuen Machttechniken, S. Fischer, Frankfurt am Main, 2014.

Han, B.: Die Austreibung des Anderen: Gesellschaft, Wahrnehmung und Kommunikation heute, S. Fischer, Frankfurt am Main, 2016.

Hannah, M.: Skeptical realism: from either/or to both-and, Environ. Plann. D, 17, 17-34, https://doi.org/10.1068/d170017, 1999.

Hannah, M.: Rezensionsaufsatz: Zum anti-deterministischen Geist in der Geographie, Geogr. Helv., 66, 54-59, 2011.

Hannah, M.: Aufmerksamkeit und geographische Praxis, Geogr. Z., 103, 131-150, 2015.

Hard, G.: Geographie als Spurenlesen: Eine Möglichkeit, den Sinn und die Grenzen der Geographie zu formulieren, Z. Wirtsch., 33, 2-11, 1989.

Heidegger, M.: Die Frage nach dem Ding: Zu Kants Lehre von den transzendentalen Grundsätzen, Max Niemeyer, Tübingen, 1962.

Heidgen, M., Koch, M., und Köhler, C.: Permanentes Provisorium: Hans Blumenbergs Umwege, Wilhelm Fink, Paderborn, 2015.

Heinrich, K.: Parmenides und Jona: Vier Studien über das Verhältnis von Philosophie und Mythologie, Suhrkamp, Frankfurt am Main, 1966.

Heinrichs, H.-J.: Peter Sloterdijk: Die Kunst des Philosophierens, Hanser, München, 2009.

Horkheimer, M.: Montaigne und die Funktion der Skepsis [1938], in: Kritische Theorie: Eine Dokumentation, Band II, 201-260, S. Fischer, Frankfurt am Main, 1968.

Jaspers, K.: Nikolaus Cusanus, dtv, München, 1968.
Kallscheuer, O.: Spiritus Lector: Die Zerstreuung des Zeitgeistes, in: Peter Sloterdijks „Kritik der zynischen Vernunft“, Suhrkamp, Frankfurt am Main, 7-72, 1987.

Köhne, W.: Zeitzeugenschaft im Verborgenen. Der Philosoph als Seismograph der geistigen Situation der Zeit, in: Die Kunst des Überlebens: Nachdenken über Hans Blumenberg, Herausgeber: Wetz, F. J. und Timm, H., Suhrkamp, Frankfurt am Main, 409425, 1999.

Korf, B.: Geographie des Ernstfalls, Geogr. Z., 97, 151-167, 2009.

Korf, B.: Die Ironie der Entwicklung, Geogr. Z., 106, 150-174, 2018.

Korf, B. und Verne, J.: Editorial: Geographie als Geisteswissenschaft - Geographie in den Geisteswissenschaften, Geogr. Helv., 71, 365-368, https://doi.org/10.5194/gh-71-365-2016, 2016.

Lang, B.: Jesus der Hund: Leben und Lehre eines jüdischen Kynikers, C.H. Beck, München, 2010.

Lossau, J.: Politik der Verortung: Eine postkoloniale Reise zu einer „ANDEREN“ Geographie der Welt, Transcript, Bielefeld, 2002.

Marquard, O.: Skeptische Methode im Blick auf Kant, Karl Alber, Freiburg, 1958.

Marquard, O.: Schwierigkeiten mit der Geschichtsphilosophie, Suhrkamp, Frankfurt am Main, 1973.

Marquard, O.: Exile der Heiterkeit, in: Das Komische: Poetik und Hermeneutik VII, Herausgeber: Preisendanz, W. und Warning, R., Wilhelm Fink, München, 133-151, 1976.

Marquard, O.: Abschied vom Prinzipiellen, Reclam, Stuttgart, 1981.

Menke, C.: Zweierlei Übung: Zum Verhältnis von sozialer Disziplinierung und ästhetischer Existenz, in: Michel Foucault: Zwischenbilanz einer Rezeption, Herausgeber: Honneth, A. und Saar, M., Suhrkamp, Frankfurt am Main, 283-299, 2003.

Meyer, T.: Der Mann in der Tonne, Karl Marx, der Grossinquisator und wir. Anmerkungen zur philosophischen Grundlegung der Tunix-Bewegung, in: Peter Sloterdijks ,Kritik der zynischen Vernunft“, Suhrkamp, Frankfurt am Main, 189-228, 1987.

Niehues-Pröbsting, H.: Der Kynismus des Diogenes und der Begriff des Zynismus, Suhrkamp, Frankfurt am Main, 1988.

Niehues-Pröbsting, H.: Blumenbergs Platonlektüre, kritisch betrachtet, in: Prometheus gibt nicht auf: Antike Welt und modernes Leben in Hans Blumenbergs Philosophie, Herausgeber: Möller, M., Wilhelm Fink, Paderborn, 25-46, 2015.

Philo, C.: A ,new Foucault" with lively implications - or "the crawfish advances sideways“, T. I. Brit. Geogr., 37, 496-514, https://doi.org/10.1111/j.1475-5661.2011.00484.x, 2012.

Raju, S. und Jeffrey, A.: Critical geography, in: The International Encyclopedia of Geography, Herausgeber: Richardson, D., Castree, N., Goodchild, M. F., Kobayashi, A., Liu, W., and Richard, A. M., John Wiley, Hoboken, NJ, https://doi.org/10.1002/9781118786352.wbieg1045, 2017.

Redepenning, M.: Die Moral der critical geopolitics, Geogr. Z., 95, 91-104, 2007.

Reichel, J.: Zwischentöne und Untergründe. Eine rezeptionsästhetische Annäherung an Hans Blumenbergs „Kleine Schriften“, in: Prometheus gibt nicht auf: Antike Welt und modernes Leben in Hans Blumenbergs Philosophie, Herausgeber: Möller, M., Wilhelm Fink, Paderborn, 203-218, 2015.

Runkel, S. und Everts, J.: Geographien sozialer Krisen/Krisen sozialer Geographien, Geogr. Helv., 72, 475-482, https://doi.org/10.5194/gh-72-475-2017, 2017. 
Saar, M.: Einleitung: Zwischen Ethik und Ästhetik, in: Michael Foucault: Zwischenbilanz einer Rezeption, Herausgeber: Honneth, A. und Saar, M., Suhrkamp, Frankfurt am Main, 277-282, 2003.

Saar, M.: Nachwort: Die Form des Lebens: Künste und Techniken des Selbst beim späten Foucault, in: Foucault, Michel, Ästhetik der Existenz: Schriften zur Lebenskunst, Suhrkamp, Frankfurt am Main, 319-343, 2007.

Schües, C.: Das Lachen der thrakischen Magd: Über die „Weltfremdheit" der Philosophie, Bochumer Philosophisches Jahrbuch für Antike und Mittelalter, 13, 15-31, 2008.

Sens, E.: Tun und Lassen. Stichworte zur Kritik des zynischen Handelns, in: Peter Sloterdijks „Kritik der zynischen Vernunft“, Suhrkamp, Frankfurt am Main, 252-263, 1987.

Sloterdijk, P.: Michel Foucaults structurale Theorie der Geschichte, Philos. Jahrb., 79, 161-194, 1972.

Sloterdijk, P.: Kritik der zynischen Vernunft, Suhrkamp, Frankfurt am Main, 1983.

Sloterdijk, P.: Der Denker auf der Bühne. Nietzsches Materialismus, Suhrkamp, Frankfurt am Main, 1986.

Sloterdijk, P.: Eurotaoismus: Zur Kritik der politischen Kinetik, Suhrkamp, Frankfurt am Main, 1989.

Sloterdijk, P.: Sphären I: Blasen, Suhrkamp, Frankfurt am Main, 1998.

Sloterdijk, P.: Die Kritisch Theorie ist tot, Die Zeit, S. 35, 9 September (Nr. 37), 1999.

Sloterdijk, P.: Nicht gerettet: Versuche nach Heidegger, Suhrkamp, Frankfurt am Main, 2001.

Sloterdijk, P.: Ach, Professor!, Frankfurter Allgemeine Zeitung, S. 35, 26 September (Nr. 224), 2009a.

Sloterdijk, P.: Du musst dein Leben ändern: Über Anthropotechnik, Suhrkamp, Frankfurt am Main, 2009b.

Sloterdijk, P.: Scheintod im Denken. Von Philosophie und Wissenschaft als Übung, Suhrkamp, Frankfurt am Main, 2010.

Sommer, A. U.: Kurze Ideengeschichte des Idioten, Zeitschrift für Ideengeschichte IV, 2, 5-19, 2010.
Steinbrink, M. und Aufenvenne, P.: Über Othering, Entgrenzung und Mainstreaming der Neuen Kulturgeographie, Eine kleine Disziplinbeobachtung, MItteilungen der Österreichischen Geographischen Gesellschaft 159, 83-104, 2017.

Strasser, P.: Idioten des Absoluten: Über das Weltfremde in uns, Wilhelm Fink, Paderborn, 2017.

Strauss, B.: Heideggers Gedichte. Eine Feuerprobe unserer kommunikativen Intelligenz: Zum einundachtzigsten Band der Gesamtausgabe, in: Heidegger und die Literatur, Herausgeber: Figal, G. und Raulff, U., Vittorio Klostermann, Frankfurt am Main, 9-16, 2012.

Strauss, B.: Lichter des Toren: Der Idiot und seine Zeit, Diederichs, München, 2013.

Strüver, A.: „Das duale System“: Wer bin ich - und wenn $\mathrm{ja}$, wie viele? Identitätskonstruktonen aus feministischpoststrukturalistischer Perspektive, in: Kulturgeographie: Aktuelle Ansätze und Entwicklungen, Herausgeber: Gebhardt, H., Reuber, P., und Wolkersdorfer, G., Spektrum, Heidelberg, 113-128, 2003.

Verne, J.: Ethnographie und ihre Folgen für die Kulturgeographie: eine Kritik des Netzwerkkonzepts in Studien zu translokaler Mobilität, Geogr. Helv., 67, 185-194, https://doi.org/10.5194/gh-67185-2012, 2012.

Vogl, J.: Über das Zaudern, diaphanes, Zürich, 2008.

Wetters, K. und Fuchs, F.: Skepsis, in: Blumenberg lesen: Ein Glossar, Herausgeber: Buch, R. und Weidner, D., Suhrkamp, Frankfurt am Main, 276-290, 2014.

Zahnen, B.: Fragwürdigkeit und Eigensinn der Geographie, Geographische Zeitschrift, 93, 201-220, 2005.

Zahnen, B.: Geographievergessenheit, Divinatio, 34, 197-228, 2011.

Zill, R.: Auch eine Kritik der reinen Rationalität: Hans Blumenbergs Anti-Methodologie, in: Permanentes Provisorium: Hans Blumenbergs Umwege, Herausgeber: Heidgen, M., Koch, M., und Köhler, C., Wilhelm Fink, Paderborn, 53-74, 2015.

Žižek, S.: The Sublime Object of Ideology, Verso, London, 1989. 